\title{
AgressividAde E VIOLÊNCIA
}

\author{
Ilka Franco Ferrari1*
}

\section{RESUMO}

Um percurso pela obra de Freud e Lacan que objetive esclarecer conceito e usos dos termos agressividade e violência conduz ao esclarecimento de que tais termos não se superpõem, ainda que possam estar interligados. O contexto em que aparecem sempre supōe algo de renúncia por parte do sujeito, devido ao tratamento que a civilização dá ao gozo. A agressividade, porém, está circunscrita à estruturação do eu enquanto a violência se ordena em torno da lógica que implica a entrada do vivente na linguagem, que não é sem conseqüências. São consideradas questōes atuais sobre o tema, a partir das coordenadas do discurso capitalista e suas implicaçõos subjetivas.

Palavras-chave: agressividade, violência, Freud, Lacan

\section{ABSTRACT}

AgGRESSIVENESS AND VIOLENCE

A journey through Freud and Lacan's work to clarify the concept and usages of the terms aggressiveness and violence leads to the conclusion that those terms are not superposed, although they are related. The context in which they appear always suppose some sort of renouncement on the part of the subject, resulting from the treatment civilization gives to enjoyment. On the other hand, aggressiveness is circumscribed to the ego's constitution process, while violence organizes itself according to a logic which implies men's entrance into language, a process that is not without consequences. Contemporary issues are discussed, as the capitalism discourse and its implications to subjectivity.

Keywords: aggressiveness, violence, Freud, Lacan

* Professora na Graduação e no Programa de Mestrado em Psicologia da PUC-Minas; Membro aderente da Escola Brasileira de Psicanálise, Minas Gerais; Membro do Comitê de Ética da PUC-Minas; Membro da Comissão de Acompanhamento Permanente de Egressos da PUC-Minas; Membro do Colegiado de Coordenação Didática do Programa de Mestrado da PUC-Minas. 
A preocupação em distinguir os termos agressividade e violência, a partir de Freud e Lacan, levará o interessado à constatação de que a violência não chega a ter o estatuto de um conceito psicanalítico, embora seu uso em psicanálise difira do uso popular. A agressividade, no entanto, é abordada com objetivos conceituais. Por outro lado, a busca dos usos que Freud e Lacan fizeram desses dois termos coloca o estudioso diante de preocupações dos autores com a clínica e com a civilização.

\section{EM TODOS OS TEMPOS}

A história da humanidade é repleta de atos considerados violentos e agressivos, já descritos até mesmo na Bíblia e na filosofia clássica, a exemplo de Platão (1990), no Livro IX da República. Nele Platão faz um retrato do homem tirânico, o mais violento dos homens, já que é hospedeiro de todos os vícios. Sendo assim, situá-los no coração da civilização, como o fez Freud, parece mais sensato que buscar estatísticas e preocupar-se em avaliar se antes havia mais ou menos atos considerados agressivos e/ou violentos que hoje.

O contexto sócio-histórico faz com que a agressividade e/ou a violência tenham suas formas fenomênicas de expressão alteradas. Assim, pensar um pouco sobre as formas de manifestação do que se denomina violência na atualidade ${ }^{1}$ é deparar-se com um espetáculo que pode ser acompanhado, ao vivo, por imagens que refletem o descuido com a dimensão simbólica da vida, exposta pelos meios de comunicação. É deparar-se, ainda, com a peculiaridade de não saber onde esperá-la, embora possa ocorrer a qualquer instante. Esse foi um dos motivos que levou o psicanalista Jacques Alain-Miller a dizer que estamos em um mundo de guerras permanentes e o historiador e pesquisador brasileiro Luís Mir $^{2}$ (2005) a caracterizar estes tempos como época de guerra civil. Como se deduz, nessa época a violência se transformou em um fenômeno com discurso que lhe é próprio. Nesse discurso, infelizmente, o que importa é reduzi-la à objetividade de sua constatação, contabilizando-a, demonstrando-a por meio de estatísticas. O sentido que ela porta pouco importa. Nesse cenário, a generalização da idéia de trauma cria o roteiro para as vítimas, os estressados, os pedintes de castigo e vigilância preventiva, apoiados e resguardados pelos Direitos Humanos e pelo ideal democrático (Ferrari, 2004).

\section{AlÉM DOS FENÔMENOS}

Em Freud e Lacan, autores-referência, verifica-se constante preocupação com o que se passa na cultura, para além dos fenômenos observados. Poder-se-ia arro- 
lar aqui inúmeros dizeres de Freud sobre o tema. Basta, porém, recordar que Lacan, leitor cuidadoso de Freud, foi contundente ao afirmar que deveriam desistir de praticar a psicanálise os praticantes que não considerem a subjetividade de sua época (Lacan, 1953/1998: 322).

Não há mesmo como desconsiderar as coordenadas discursivas de uma época e suas ocorrências subjetivas quando se está na dimensão psicanalítica. Ainda mais se a subjetividade é considerada como um "sistema organizado de símbolos que aspiram abranger a totalidade de uma experiência, animá-la, dar-lhe sentido" (Lacan, 1954-55/1987: 58).

$\mathrm{Na}$ atualidade, a subjetividade dos sujeitos traz as marcas do que Lacan denominou discurso capitalista. Isso não se pode esquecer. $\mathrm{O}$ próprio Lacan ensinou uma forma psicanalítica de se considerar a questão: com Marx falou de plusvalia como causa de desejo do capitalista, mas depois percebeu que, quando se está na plus-valia como causa de desejo, o que há é um regime de falta de gozar. Encontrou-se, nesse ponto, com a concepção do capitalismo como cultura de falta de gozar, expressa por Max Weber. Isso significa que o capitalista não é puramente um gozador, já que o capital é reinvestido no regime. Assim, em "Radiofonia" (1970/2003), Lacan afirma que a plus-valia é a causa de desejo de toda economia, ou seja, do proletário e do capitalista. Se todos têm como causa a plus-valia, é porque estão na avidez da falta de gozar. Conclui que, nesse regime, todos são proletários, despossuídos, nada têm para estabelecer laço social, vivem em insatisfação permanente, expressa na fórmula do nunca é bastante e na busca constante de um plus.

É nessa situação que a violência se confunde com a agressividade e que o termo violência torna-se uma categoria ampla, comportando inúmeros fenômenos, o que a torna pouco precisa. Isso já não ocorre na disciplina conhecida como psicanálise, ainda que, como cidadão, o psicanalista não ignore o que se passa na cidade.

Na psicanálise, a violência é vista sempre em um referencial que mostra que o encontro com a linguagem não é sem conseqüências para o humano. Compreender a violência por meio desse ensino supõe adentrar-se na constituição do laço social, considerar os discursos que imperam em dado contexto histórico e não perder de vista as formas como os sujeitos são capazes de responder aos mesmos, já que a pulsão está presente também em momentos pacíficos.

Com referência à agressividade, tanto Freud quanto Lacan situam-na como constitutiva do eu, na base da constituição do eu e na sua relação com seus objetos. Não negam sua existência, ao contrário, afirmam a agressividade na ordem humana, ordem libidinal. Existe a agressividade, mas ela pode ser sublimada, pode 
ser recalcada, não precisa ser atuada, pois o humano conta com o recurso da palavra, da mediação simbólica.

Preocupado com essa questão, Lacan (1948/1998) até esboçou uma clínica diferencial entre neurose e psicose, por meio da noção de intenção e tendência agressiva. Na neurose, a agressividade se apresenta mediante a intenção agressiva. É intencional porque supõe um querer dizer, mas, paradoxalmente, uma vontade de impedir o sentido. Há intenção de significação nessa agressividade, isto é, na neurose ela é decifrável como um sintoma. Assim, ela é forma de comunicação com o outro, o que levou Lacan a desenvolver a noção de reivindicação, depois transformada em demanda, ou seja, em dirigir-se ao outro pedindo algo do que se julga merecedor. Já na psicose, há tendência agressiva, vinculada ao Kakon, a algo objetivado, algo que não conta com uma interpretação.

\section{CONSIDERAÇÕES}

Um bom exemplo da preocupação dos psicanalistas com a subjetividade da época é o texto "A agressividade em psicanálise" (Lacan, 1948/1988), escrito no pós-guerra. Segundo Miller (1999), naquela época o mundo estava perplexo com os feitos de Hitler, mas os europeus ainda permaneciam muito apreensivos em relação a Stalin e àquilo que os Estados Unidos poderiam fazer para proteger a Europa, já que se conhecia o que ocorrera em Hiroshima. Eram tempos em que os "psi" se voltavam para essa questão. Aliás, não só Lacan escreveu sobre o tema. Também o fizeram, conforme enfatiza Miller, Hartmann, Lowenstein e Kris, defensores da psicologia do eu, como mostra o texto "Notas sobre la teoria de la agresión”, publicado em 1949 (Miller, 1991).

Também são bem conhecidas as contribuições de Freud relativas aos momentos de guerra e paz. Muito se menciona só o que Freud escreveu a esse respeito e vale lembrar, aqui, as afirmações de Albert Einstein, na correspondência que manteve com Freud (Freud, 1933/1974). No texto originado dessa correspondência, favorecida pela Liga das Nações, antecessora da Organização das Naçôes Unidas, Einstein assinala que a ciência era uma novidade, mas trazia perigos ainda maiores à humanidade. Já sinalizava uma perigosa aliança entre ciência e capital, favorecedora de violência. A seu estilo, Freud não cansou de assinalar esse rumo: o mundo, estruturado pela ciência e dirigido pela razão, abandonava, radicalmente, o sujeito que ele, Freud, tanto valorizava. Isso não seria sem conseqüências.

Lacan também não hesitou em mostrar o caráter inumano da ciência, o que levou a psicanálise a encontrar seu lugar, sempre, no mal-estar da cultura. Não 
cansou de convidar a ciência ao diálogo, por meio dos caminhos percorridos por Bachelard, Koyré e a ciência moderna (Ferrari, 2002).

Os tempos atuais também contam, notoriamente, com a preocupação e com o trabalho de psicanalistas de diferentes escolas. Mudanças na clínica são evidenciadas e enfatizadas. Diz-se, então, de sintomas contemporâneos, de patologias do ato, entre outras expressões, para indicar a característica peculiar desses sintomas que resistem ao trabalho que usa a palavra, diferentemente da época freudiana. São os sintomas próprios de um mal-estar subjetivo que supõe evitar o conflito interior por meio do não-exercício do pensamento, mesmo que manifestos por sujeitos que tenham condições de pensar. Como é bem conhecido, nessas formas sintomáticas têm sido incluídas as anorexias, bulimias, toxicomanias, mas, também, a violência.

Nesse contexto, hoje se diz, então, de violência como sintoma. A compreensão dessa afirmativa pode ser facilitada quando se pensa que todo sintoma, no sentido psicanalítico, é uma emergência de verdade que concerne ao gozo, é um gozo. Sintoma, como tanto já se escreveu, é o que condensa verdade e gozo. A violência, que é sintoma, supõe, então, uma ordem instituída da qual emerge, manifestando aquilo que não funciona bem em tal ordem estabelecida, aquilo que impede a intenção de felicidade, ou melhor, que impede o princípio do prazer. Miller, em "O Outro que não existe e seus comitês de ética” (2005: 18), pergunta o que é uma civilização e responde que uma civilização é um sistema de distribuição do gozo a partir de semblantes, um modo de gozo, uma distribuição sistematizada dos meios e maneiras de gozar.

Posto isso, a violência atual, colocada na ordem de sintoma, mostra, como todo sintoma, que o gozo não caminha no ritmo dos significantes mestres, dos semblantes ordenadores da civilização. Ela é forma de expressar que algo não vai bem na ordem instituída pela civilização, no caso atual ordenada pelo sistema capitalista e seu mais gozar.

\section{RECORTES FREUDIANOS}

Foi a prática clínica que ensinou a Freud o que ele deixou de legado sobre a agressividade. Rastrear o assunto em sua obra é dispor-se, então, a uma árdua tarefa. Significa deparar-se com a constituição do eu/não-eu, prazer/desprazer, amor/ódio, ideal do eu/eu ideal, auto-erotismo, narcisismo, sadismo, masoquismo e, principalmente, com a tendência restituitória e a pulsão de morte. Supõe o encontro com o mito do Pai da horda primitiva e exige o esforço de clareza dos termos hostilidade, crueldade, intenção e tendência agressiva, todos eles jogando 
com Eros e Thanatos. Em sua obra, o termo violência é utilizado em seu sentido popular. Nela é possível, entretanto, observar elaboraçôes teóricas que tocam o cerne da questão da violência, própria da linguagem, quando desenvolve o tema da agressividade.

Em Freud, a agressividade humana não é a que se observa em outros animais, expressa na luta pela conservação da espécie. É bem verdade que sua primeira tópica se aproxima da fenomenologia evolucionista, ao percorrer os caminhos da subjetividade pela via do egoísmo e do ciúme, com a criança apreendendo o prazeroso e desprezando o fruto de desprazer. Aproxima-se da noção de instinto animal e nela não permanece porque a agressividade humana para ele demonstra outra herança: a inscrita na ordem social, referente à herança de uma lei a que o humano se submete e faz com que ele articule proibição, hostilidade e ética, como no mito "Totem e tabu”.

Dessa forma, para Freud, no humano há hostilidade e ódio. Tais afetos expressam que há uma intenção agressiva por parte do eu, ou seja, algo diferente de instinto agressivo. Hostilidade e ódio dirigidos ao outro que põem em perigo um prazer que não quer dividir manifestam-se sob diferentes formas: "olhar, ironia, insulto, chiste obsceno e até ódio declarado" (Gallo, 1991: 64). Ódio é a versão originária da hostilidade e ambos estão, dessa forma, na base do princípio do prazer. A crueldade, forma de dizer da agressividade no registro da ação direta contra o outro ou contra si mesmo, tal como pode ser observada no sadomasoquismo, também é algo próprio dos humanos, segundo Freud.

A base da crueldade, para Freud, é o egoísmo, próprio de toda satisfaçãosexual-biológica. Sendo dessa ordem, a crueldade não supõe consideração ao outro. Originando-se nas fases pré-genitais da libido, quando ainda não se formou a compaixão pelo sofrimento do outro, e obedecendo ao impulso de apreensão do objeto, a crueldade favorece a passagem ao ato. Daí o valor atribuído por Freud à adolescência, por ser um período importante, um momento privilegiado de identificação que favorece a humanização dos adultos. Ele não deixa de considerar, no entanto, que existem situaçôes nas quais se constata tendência à crueldade no adulto; principalmente, no adulto masculino. O sadomasoquismo é exemplo do fracasso da compaixão social, fracasso da inibição da crueldade, que faz com que a dor do outro traga prazer e mostre uma divisão subjetiva entre a intenção destrutiva e a tendência ao castigo.

Afinal, pode-se dizer que as considerações freudianas sobre a constituição de um ideal pelo eu, bem como sobre o narcisismo, ampliam os estudos que comportam a existência da agressividade no humano. O ideal é visto como favorecedor do recalque e, conseqüentemente, da civilização, das trocas entre os cidadãos. 
Com o narcisismo, cujo desenvolvimento teórico o levou a reformular a teoria das pulsões, Freud observou, por meio das psicoses, que os investimentos libidinais em objetos do mundo externo podem retornar ao eu do sujeito. Além do mais, basta uma intenção hostil sobre o amor a si mesmo, sobre o eu, que é o objeto de investimento, para desagregar a subjetividade. Daí em diante, as formulações sobre a pulsão de morte (Freud, 1915/1974), a repetição e o masoquismo primário são fundamentais.

No que se refere à repetição, ela mostrou a Freud que, em nome do princípio do prazer, a criança se aliena no desejo do Outro, como diria Lacan. Mostrou-lhe, ainda, que havia algo diferente, algo da ordem de uma compulsão à repetição na qual aquilo que, de forma alguma, podia ser fonte de prazer se impunha. Havia, assim, algo mais além do princípio do prazer, além e diferente do que havia sido chamado repetição. Era a pulsão de morte escancarando ao autor o fato de haver, no humano, uma tendência de retorno à ordem inanimada, pois o objetivo de toda vida é a morte. Em vista disso, as interações humanas já não se apresentam simples. Exigem um grande esforço. Com efeito, a pulsão de morte foi a forma encontrada por Freud para dizer que o sujeito se edifica sobre um fundo que supõe destruição. $\mathrm{O}$ masoquismo primário, mencionado em "Além do princípio do prazer" (Freud, 1920/1974) e desenvolvido quatro anos depois, no artigo "O problema econômico do masoquismo" (Freud, 1924/1974), é um exemplo da expressão de que a vida é prisioneira da morte.

De modo geral, pode-se dizer que narcisismo, masoquismo primário e repetição foram os últimos caminhos a que Freud foi levado, quando se defrontou com as formas com que o vivente ${ }^{3}$ se posiciona de acordo com o mundo dos ideais sociais e dos valores elevados. Ao partir da tendência que o eu ainda incipiente tinha para suprimir o que lhe era estranho, ameaçador para sua economia prazerdesprazer, chegou a colocar o humano, em seu processo singular, como um inimigo potencial da civilização.

As formalizações sobre a agressividade vão se tornando mais complexas ao final de sua obra. Ela já não se encontra sob as coordenadas da sexualidade infantil, encarada como um egoísmo que implica nada querer saber sobre o próximo, na crença de que o eliminando assegurar-se-ia o prazer. A agressividade, no final de seu ensino, é, ainda, diferente da ambivalência, dos ciúmes edípicos que visavam conservar um território conquistado, que não a distinguia do sadismo e da crueldade. Ao ligar masoquismo com excitação sexual, Freud fez equivaler dor e prazer, equivalência que deixava à agressividade só o caminho da destruição. Destinava-se à apreensão do objeto e sua dominação, por vias distintas das do amor cortês. Nesse momento, ela já não está no nível da intenção agressiva, mas a servi- 
ço da libido, com a ajuda do sistema muscular, na luta para tornar a pulsão de morte inofensiva. No interior do sujeito, como há a pretensão de tornar a pulsão de morte inofensiva, a agressividade passa a ser vista como versão de Eros. Mas, colocada no exterior, ela é destruição, versão da pulsão de morte. Ela é libido disposta a se misturar com a sexualidade para formar o sadismo e com a vontade de morte sexualizada para formar o masoquismo erógeno (Gallo, 1991: 62).

Conforme se nota, a compulsão à repetição mostrou a Freud que a agressividade não diz da desintegração do ser vivo, mas da forma ruidosa que ele encontra para se preservar na cultura. Se há no humano uma obsessão para restituir o equilíbrio, o que repete é a pulsão de morte, verdade impossível, em uma compulsão que afirma a ausência de homeostase no vivo.

\section{RECORTES LACANIANOS}

Lacan (1948/1998), ao abordar a agressividade, o faz na tentativa de construir um conceito psicanalítico para a mesma (Miller, 1991). Em 1948, ainda não dizia fazer o retorno a Freud, mas estava às voltas com o conceito de pulsão de morte, que considerava ser o testemunho da aporia freudiana, ou seja, aquilo que não permitiu a Freud ir além. Segundo Lacan, Freud, ao formalizar a pulsão de morte, tentou dar uma fórmula biológica da experiência e acabou por demonstrar sua impossibilidade. Lacan partiu, então, da teoria do narcisismo freudiano e construiu outro conceito de eu, considerado a partir da Verneinung e do narcisismo, diferente do eu freudiano, que se baseava no sistema percepção-consciência, na adaptação à realidade. Desse modo, tentou resolver a questão da aporia freudiana.

Os textos do pós-guerra como "Formulações sobre a causalidade psíquica" (1946/1998), "A agressividade em psicanálise" (1948/1998) e "Introdução teórica às funções da psicanálise em criminologia" (1950/1988) dão testemunho da tentativa lacaniana de recuperar a noção de pulsão de morte, abandonada por alguns pós-freudianos, ainda que continuassem falando de agressividade.

Afinal, para Lacan, o fundamento da agressividade é a identificação narcísica e a estrutura do eu. Nesse sentido, a elaboração freudiana sobre o narcisismo favoreceu a afirmação lacaniana de que a agressividade é constitutiva da primeira individuação do sujeito, conforme se observa na tese central, tese IV, apresentada em "A agressividade em psicanálise” (1948/1998). Segundo Lacan, não há identificação sem agressividade e tampouco agressividade sem identificação. Tal identificação supõe um desgarramento original do sujeito, deixando na subjetividade a paranóia original, ou seja, a marca da relação agressiva com o outro. Assim, a relação com o outro é fundamentalmente agressiva, ainda que sublimada. Se a 
agressividade pode ser sublimada, Lacan, no entanto, "nunca renunciou à idéia de que, no nível profundo, o que há é a hostilidade e não a harmonia” (Miller, 1991: 19). Como exemplo dessa afirmativa, Miller assinala que basta olhar as formulaçôes sobre a constituição do sujeito, as elaboraçôes sobre a castração, sobre o supereu e o Outro, Outro que quase poderia ser escrito com o "A" de agressor.

Sobre o eu lacaniano, observa-se que ele é uma instância de méconnaissance, pois seus fundamentos são a Verneinung e o narcisismo. Supõe um poder de ilusão, de mentira, de surgimento de outra coisa no lugar desse desconhecimento. Situada na especularidade imaginária, a agressividade é elaborada no que Lacan chamou estágio do espelho. Em sua primeira individuação, identificação primária, surge o sujeito que se estrutura rivalizando consigo mesmo, já que constrói uma imagem que o aliena em uma organização passional a que chamará "eu". $\mathrm{O}$ eu surge, então, de uma tensão interna, determinando o despertar do desejo pelo objeto de desejo do outro. Aparece a rivalidade agressiva e a tríade composta pelo próximo, o eu e o objeto.

Vinculada à estrutura do eu, a agressividade assume caráter permanente e faz com que o estágio do espelho constitua a paranóia estrutural do homem.

Não foi sem sentido que Lacan esteve, então, sempre procurando o que seria o possível elemento pacificador dessa paranóia estrutural, o que permitiria aos homens viverem juntos, estando separados. Abordou a função sublimatória da identificação e depois deixou ao simbólico o papel de pacificar a paranóia, a agressividade imaginária. Ao escrever $O$ avesso da psicanálise (1969-1970/1992), a pacificação surge pela necessidade de respeitar o significante mestre. Interessante é não esquecer que Lacan dava uma dupla função ao significante mestre: a de pacificação, mas também de uma violência, que é própria da linguagem (isso será comentado adiante). Nessa pacificação da tensão imaginária, agressiva, são encontradas, então, as vicissitudes do Édipo e os efeitos do ideal do eu. Isso porque o sujeito, dividido pelo semelhante, se sente agredido e agressor, inclusive de si próprio. $\mathrm{O}$ supereu, nessa circunstância, nada mais é que a expressão da divisão do sujeito contra ele mesmo.

Por outro lado, observa-se que, após a escrita do texto "A agressividade na psicanálise" (1948/1988), o conceito de agressividade não aparece, de forma relevante, no restante da obra de Lacan, embora ele jamais tenha abandonado a tese da dimensão imaginária da mesma, conforme assegura Miller (1991).

De fato, no seminário sobre As formaçōes do inconsciente (1957-58/1999), Lacan enfatiza que o uso do termo agressividade estava carregado de ambigüidades e alerta que a agressividade, provocada na relação imaginária com o outro, não podia ser confundida com a potência agressiva. Logo após, parece associar potên- 
cia agressiva à violência, ao afirmar que a violência "é, certamente, o essencial na agressão, pelo menos no plano humano. Não é a palavra; inclusive, é exatamente o contrário. $\mathrm{O}$ que se pode produzir em uma relação inter-humana é a violência ou a palavra" (1957-58/1999: 468). Lacan demarca uma violência que supõe ato de agredir diante do impossível de dizer, supõe possibilidades de passagem ao ato, curto-circuito da palavra, retornando, no real, o gozo que escapa ao sentido. Nessa mesma página, ele faz referência à "violência propriamente dita" para distinguila, conforme esclarece, "do uso que fazemos do termo agressividade". Aborda essa distinção a partir da noção de recalque e da possibilidade de interpretação. Se, de acordo com o princípio da psicanálise lacaniana, só se recalca o que acedeu à estrutura da palavra, a uma articulação significante, como lembra Lacan, pode-se perguntar em que medida é possível recalcar a violência, aqui colocada fora do alcance da palavra. Ademais, o "uso que fazemos do termo agressividade" é uma referência às construções freudianas organizadas por ele no estágio do espelho, ou seja, no âmbito da rivalidade especular com o semelhante. Para Lacan, aquilo que é da ordem da agressividade pode chegar a ser simbolizado e captado pelo mecanismo do recalque; portanto, possível de ser interpretado.

Nunca é demais lembrar que, com o avanço de seu ensino, Lacan introduz a noção de significante, que ora aparece em seu efeito de violência para o vivente, efeito mortificante, mas, principalmente, em seu efeito de vida para $o$ falasser ${ }^{4}$. Tal constatação exige que se considere, ao ler o texto "A agressividade em psicanálise" (1948/1988), a anterioridade desse texto à referência lingüística de Lacan. Conseqüentemente, exige recordar que o inconsciente é, ali, o lugar onde permanecem as imagos ${ }^{5}$, imagos essas que podem ser reanimadas por um acontecimento na vida ou na experiência analítica.

Foi a partir da noção do simbólico como pacificador, embora o imaginário permaneça paranóico, que Lacan abordou o insulto ou injúria como o limite da relação simbólica com o outro, por meio da palavra. Referindo-se a Schreber, ele diz: "A injúria é a outra face, a contraparte do mundo imaginário [...] A injúria aniquiladora é um ponto culminante, é um dos cumes do ato da palavra" (Lacan, 1955-56/1988: 118). No Seminário 5 (1957-58/1999), Lacan faz questão de diferenciar a injúria da blasfêmia, que é própria do obsessivo. A primeira mostra a destruição do ser e a segunda visa rebaixar o significante supremo à categoria de objeto.

Nessas construções sobre o objeto, Lacan trabalha os dualismos amor e ódio, esclarecendo por que Freud dizia que o ódio é mais antigo que o amor. O ódio acontece na etapa de diferenciação do eu/não-eu e será, assim, uma paixão do ser que aponta para a dimensão simbólica, para o ser simbólico, objetivando destruí- 
lo. O amor, também uma paixão do ser, é fundamentalmente narcisista. Daí, o afeto ligado a Das Ding é o ódio acompanhado de paixão destrutiva e o registro imaginário está excluído da dialética do ódio. Não há, para Lacan, conforme se observa, a confusão em que se embrenhou Freud, entre agressividade e destrutividade. Aliás, é bastante comentada a diferença que traça Lacan entre um aniquilamento imaginário e outro simbólico, por meio das "duas mortes", comentadas nos Seminários A ética (Lacan, 1959-60/1991) e A transferência (Lacan, 1960-61/ 1992). O simbólico, como já se comentou, ora aparece como pacificador e vivificador; ora como agressor e gerador de agressividade, já que a estrutura da linguagem exige que o sujeito sacrifique algo de si, tal como ensina a teoria do falo e da angústia de castração simbólica.

Por esse recorte, observa-se que Lacan apresenta elementos que tornam mais clara a distinção entre violência e agressividade. Com ele torna-se possível dizer da violência a partir do ponto de vista da pulsão e do discurso, nos registros real e simbólico. E pensá-la no registro simbólico é indagar-se sobre uma violência que está na base do laço social, conforme ensina "Totem e tabu" (1913/1974). A própria noção de contrato social, ato simbólico, supõe uma violência ao real, pois seu princípio é o de uma ordem universalizante. Como se sabe, o real não é o mesmo para todos. Há, então, uma violência onde o que se viola é uma ordem estabelecida, seja ela considerada da ordem da natureza ou da civilização. Pensá-la de forma simbólica é considerar a violência da própria linguagem sobre o vivente que, ao nascer, encontra o Outro do discurso. Nesse encontro, ocorre a violência de alienar-se na lei dos significantes, que são, sempre, do outro. Além disso, há a violência própria à separação do Outro, inerente ao processo de instituição subjetiva do sujeito, retirando-o da alienação significante. É nesse conceito de separação que se pode ver uma das saídas de Lacan para a aporia freudiana sobre a pulsão de morte freudiana. Em suas palavras, “[...] a pulsão parcial é fundamentalmente pulsão de morte e representa em si mesma a parte da morte no vivo sexuado" (Lacan, 1964/ 1988: 195). Assim, faz-se mais fácil pensar em violência que institui a subjetividade, que ordena o laço social, mas não se pode esquecer de sua possibilidade desagregadora.

\section{Para finalizar}

Em meio às diferenças, agressividade e violência têm algo em comum: tanto uma quanto a outra supõem algo de renúncia por parte do sujeito, uma vez que ambas supõem determinado tratamento que a civilização dá ao gozo da vida, ao gozo do vivente, àquele gozo que não é causado nem pelo significante nem por 
um objeto qualquer. Tal tratamento levou Lacan a se perguntar pelo gozo da ameba, na conferência denominada "A terceira" (Lacan, 1975/1988).

Como se pode observar, Freud e Lacan liam a cartilha da civilização. Eles não eram adivinhos. Eram trabalhadores estudiosos da psicanálise e, conforme afirmou Hebe Tizio (2004), a psicanálise sempre se antecipou à sua época, não por uma capacidade de adivinhação, mas porque é uma praxis que escuta os balbucios das mudanças nas formas atuais dos sintomas.

\section{REFERÊNCIAS BIBLIOGRÁFICAS}

Ferrari, I. F. (2002). A psicanálise no mundo da ciência. Psicologia em Revista, 11, 89-91. - (2004). Trauma e segregação. Latusa, 9, 149-162.

Freud, S. (1913 [1912-13]). Totem e tabu. Obras completas, vol. XIII. Rio de Janeiro: Imago, 1974.

- (1914). Sobre o narcisismo: uma introdução. Obras completas, vol. XIV. Rio de Janeiro: Imago, 1974.

. (1915). A pulsão e suas vicissitudes. Obras completas, vol. XIV. Rio de Janeiro: Imago, 1974.

- (1920). Além do princípio do prazer. Obras completas, vol. XVIII. Rio de Janeiro: Imago, 1974.

- (1924). O problema econômico do masoquismo. Obras completas, vol. XIX. Rio de Janeiro: Imago, 1974.

- (1933 [1932]). Por que a guerra? Obras completas, vol. XXII. Rio de Janeiro: Imago, 1974.

Gallo, H. (1991). De la agresividad a la pulsión de muerte. Em Miller, J.-A. et al. Agresividad y pulsión de muerte (pp. 59-88). Medelin: Edita f.f.m.

Lacan, J. (1946). Formulações sobre a causalidade psíquica. Em Escritos (pp. 152-194). Rio de Janeiro: Jorge Zahar, 1998.

—. (1948). A agressividade em psicanálise. Em Escritos (pp. 104-126). Rio de Janeiro: Jorge Zahar, 1998.

. (1953). Função e campo da fala e da linguagem em psicanálise. Em Escritos (pp. 238-324). Rio de Janeiro: Jorge Zahar, 1998.

- (1954-55). Uma definição materialista do fenômeno da consciência. Em $O$ seminário, livro 2: O eu na teoria de Freud e na técnica da psicanálise (pp. 57-72). Rio de Janeiro: Jorge Zahar, 1987.

- (1955-56). A dissolução imaginária. Em O seminário, livro 3: As psicoses (pp. 106-120). Rio de Janeiro: Jorge Zahar, 1988. 
. (1957-58). Los circuitos del deseo. Em El seminario, libro 5: Las formaciones del inconsciente (pp. 465-481). Buenos Aires: Paidós, 1999.

. (1959-60). Antígona no entre-duas-mortes. Em O seminário, livro 7: A ética da psicanálise (pp. 327-346). Rio de Janeiro: Jorge Zahar, 1991.

. (1960-61). No começo era o amor. Em O seminário, livro 8: A transferência (pp. 1-26). Rio de Janeiro: Jorge Zahar, 1992.

- (1964). O sujeito e o outro (1). Em O seminário, livro 11: Os quatro conceitos fundamentais da psicanálise (pp. 193-204). Rio de Janeiro: Jorge Zahar, 1988.

. (1969-1970). O avesso da psicanálise. Rio de Janeiro: Jorge Zahar, 1992.

. (1950). Introdução teórica às funções da psicanálise em criminologia. Em Escritos (pp.127-151). Rio de Janeiro: Jorge Zahar, 1998.

. (1970). Radiofonia. Em Outros escritos (pp. 404-447). Rio de Janeiro: Jorge Zahar, 2003.

(1975). La Tercera. Em Intervenciones y textos (pp. 73-108). Buenos Aires: Manantial, 1988.

Miller, J-A. (1991). La agresividad en psicoanálisis de Jacques Lacan (pp. 7-22). Em Miller, J.-A. et al. Agresividad y pulsión de muerte. Medellín: Fundación Freudiana de Medellín. . (1999). La transferencia negativa. Barcelona: ECFB.

(2005). El Otro que no existe y sus comités de ética, colaboración de Eric Laurent. Buenos Aires: Paidós.

Mir, L. (2005). Reportagem no jornal Estado de Minas de 02/02/2005.

Platão (1990). A República. Livro IX. Lisboa: Fundação Calouste Gulbenkian.

Tizio, H. (2003). Notas sobre el cuerpo sexuado. Palestra proferida na Universidade de Barcelona, Espanha.

- (2004). Conferência intitulada "El discurso analítico y su tiempo", realizada no IV ${ }^{\circ}$ Congresso da Associação Mundial de Psicanálise, em Comandatuba, Brasil, nos dias la 4 de agosto de 2004.

\section{Notas}

1 Hebe Tizio, psicanalista em Barcelona, em palestra na Universidade de Barcelona, em 2003, intitulada "Notas sobre el cuerpo sexuado", afirma que aquilo que se costuma chamar atualidade tem sempre a ver com as coordenadas do discurso de uma época.

2 Em reportagem no jornal Estado de Minas, de 2/2/05, Luís Mir fala a respeito de sua pesquisa sobre violência, que resultou no livro Guerra civil - Estado e trauma. O autor assegura que morrem, no Brasil, de forma violenta, a cada 
ano, mais de 150 mil pessoas, a maioria delas jovens. Estudioso, também, do atendimento médico aos traumatizados pela violência, afirma que o Estado para ele, o maior promotor da violência - gasta, com as vítimas da violência, $40 \%$ do total do orçamento destinado à saúde.

3 Termo retirado de Lacan, em suas elaborações sobre o gozo, sobre o real fora do simbólico. A expressão vivente refere-se ao organismo biológico, marcando a diferença do organismo com o sujeito, o eu e corpo.

4 Quando Lacan desenvolveu sua formulação sobre o parceiro-sintoma, substituiu o termo sujeito (marcado pela falta-a-ser) por falasser, para introduzir o sujeito mais o corpo vivo, substância gozante, o que supõe que o corpo é sexuado.

5 Imago é uma imagem fixa e, diferente do significante, não implica relação entre duas imagens. É imagem tipificada que tem efeitos imaginários e, também, de sentido.

Recebido em 22 de fevereiro de 2006 Aceito para publicação em 9 de novembro de 2006 